\title{
Representación cultural de la disidencia sexual en el cómic: los «hombres deseados» de Ralf König en Der berwegte Mann
}

\section{Cultural representation of sexual dissent in comics: the «desired men» of Ralf König in Der bewegte Mann}

\author{
Facundo Nazareno Saxe
}

Instituto de Investigaciones en Humanidades y Ciencias Sociales

(FaHCE-UNLP-CONICET)

Facundo Nazareno Saxe es doctor en Letras por la Universidad Nacional de La Plata, Argentina. Profesor adjunto de Literatura alemana. Investigador del CONICET (Consejo Nacional de Investiaciones Cíentificas y Técnicas). Ha dictado seminarios de grado y posgrado sobre disidencia de sexo-género y teoría queer en la UNLP y otras universidades. Su área de especialidad aborda la representación de las sexualidades disidentes en textos culturales desde una perspectiva comparada.

Fecha de recepción: 4 de marzo de 2018

Fecha de aceptación definitiva: 30 de mayo de 2018 


\title{
Resumen
}

En este artículo se abordará la representación de la sexualidad disidente en una de las obras inaugurales de Ralf König, el ciclo Der berwegte Mann, constituido por dos partes publicadas en los años ochenta y que nos permiten apreciar la emergencia del autor en el mercado editorial alemán, así como sus operaciones de resistencia ante los intentos de normalización y represión por parte de la heteronormatividad.

Palabras clave: Der berwegte Mann, disidencia, años ochenta, Ralf König, sexualidad.

\begin{abstract}
In this article, the representation of sexual dissent in German author Ralf König will be adressed. The work analize the cycle Der berwegte Mann, consisting of two parts published in the eighties and that allows us to appreciate the emergence of the author in the german publishing, as well as its operations of resistance to the attempts of normalization and repression by heteronormativity.

Keywords: Der bewegte Mann, dissent, eighties, Ralf König, sexuality.

\section{Cita bibliográfica}

SAXE, F. N. «Representación cultural de la disidencia sexual en el cómic: los "hombres deseados” de Ralf König en Der bewegte Mann», en CuCo, Cuadernos de cómic, n. o 10 (2018), pp. 7-27.
\end{abstract}




\section{Introducción}

Este artículo analiza el ciclo de historietas Der berwegte Mann de Ralf König, compuesto por dos partes publicadas en 1987 y 1988 respectivamente. Me interesa abordar en estas obras la representación ficcional de la disidencia sexual, así como la heteronormatividad, el sexo/género y los mecanismos de opresión del régimen farmacopornográfico, ${ }^{1}$ entre otras cuestiones. El trabajo será realizado desde una perspectiva queer que focaliza en la representación de la disidencia sexual y la construcción de las prácticas sexuales no normativas. Con la idea de perspectiva queer me refiero a una metodología de análisis cultural vinculada a categorías como queer, queerness y queer theory, que no resultan sencillas de definir. Me interesa pensar en algunas de las posibilidades que sugiere Alexander Doty: ${ }^{2}$ queer como sinónimo de gay-lésbico o bisexual; queer como término paraguas de lo LGBTIQ. ${ }_{i}^{3}$ queer para lo que queda al margen de lo gay-lésbico normalizado; queer para pensar algo no heterosexual; queer para describir expresiones no normativas; queer para las sexualidades disidentes; queer como subversión a lo heterosexual y lo gay «normal»; queer y queerness para pensar algo que está fuera del género establecido y las categorías de sexualidad habituales; entre otras posibilidades. Queer puede ser pensado como un término complejo, político y teórico, como una categoría de acción política que no se deja definir. En un punto, tanto la categoría queer como la teoría queer no tienen definiciones unívocas ni las necesitan (incluso se podría pensar que el potencial está en la falta de definición cerrada), queer se define en una no definición (y no una simple «indefinición»), un significado cambiante y circunstancial, lo que despierta sus posibilidades y sirve para pensar lo queer como una herramienta propia de un contexto y un momento histórico que tiene potencial para seguir pensando las sexualidades de formas amplias y diversas. En ese sentido, como señala Ceballos Muñoz, ${ }^{4}$ queer se vuelve una categoría teórica en constante movimiento, que pone en juicio las ca-

${ }^{1}$ La idea de «régimen farmacopornográfico» es desarrollada por Preciado en Testo Yonqui (2008) como un concepto determinante de su pensamiento filosófico. La invención de la categoría de género constituye el índice de emergencia del nuevo régimen farmacopornográfico de la sexualidad. El régimen farmacopornográfico es un régimen de producción al que están sometidas todas las formas de sexualidad y de producción de placer. El régimen biopolítico heterosexual es el que se conforma a finales del siglo xix y a través de un sistema científico de clasificación de los cuerpos marca binarismos anatómicos, de género o de roles sociales o sexuales; cualquier desviación se vuelve patología. Preciado, P. B. Testo yonqui. Madrid, Espasa, 2008, p. 93.

2 Doty, A. Flaming Classics. Queering the Film Canon. Nueva York, Routledge, 2000, pp. 6-7.

${ }^{3}$ La sigla corresponde a lésbico-gay-bisexual-trans-travesti-transgénero-interesexual-queer.

${ }^{4}$ Céballos Muñoz, A. «Teoría rarita», en Córdoba, D., Sáez, J. y Vidarte, P. (eds.) Teoría Queer. Politicas Bolleras, Maricas, Trans, Mestizas. Barcelona, Egales, 2005, p. 173. 
tegorías convencionales de la identidad sexual, las oposiciones y binarismos que sustentan el sistema heterosexual y la norma LGBTIQ. En lo queer la identidad deja de ser algo fijo, coherente y natural, abriendo el panorama de posibilidades sexuales que desafían la distinción entre normal/anormal, homo/hetero, masculinidad/feminidad, etc. La teoría queer desafía las categorías que construyen la normalidad sexual y se aleja de los Gay and Lesbian Studies al no querer construir un tipo de sexualidad nueva o esencial y que no asume una materialidad específica.

Este artículo pretende tomar el caso abordado como ejemplo para pensar la totalidad de la obra del autor alemán, así como su trayectoria cultural en lo que se puede denominar la primera etapa de su proyecto creador. En primer lugar, nos detendremos en el contexto histórico, la recepción crítica y el recorrido editorial de König así como los vínculos de las historietas mencionadas con el resto de la obra. En segundo lugar, abordaré la primera parte del ciclo, teniendo en cuenta las cuestiones específicas de Der berwegte Mann vinculadas a la inserción de König en el campo editorial alemán. En tercer lugar, trabajaré específicamente la segunda parte del ciclo, analizando de forma textual la expresión de la disidencia sexual y los mecanismos de disciplinamiento del sexo-género y la representación de la heteronormatividad, entre otras cuestiones. El trabajo realizado nos permite pensar estas obras, inaugurales en la carrera creativa de König, como textos que evidencian líneas de trabajo que el autor continúa desarrollando hasta sus historietas más recientes.

\section{Ralf König: historieta alemana y recepción crítica}

Ralf König es el autor de cómics más famoso y exitoso de la historia de Alemania, con una obra que juega con el humor, la ironía y el doble sentido como herramientas para combatir los prejuicios (externos e internos) de la comunidad LGBTIQ alemana. Respecto a la historieta en el contexto alemán, siguiendo a Knigge, ${ }^{5}$ Alemania no es como Bélgica, Francia, España, Italia o, incluso, Gran Bretaña que tienen una importante tradición de historieta. El desarrollo sistemático se dio luego de la Segunda Guerra Mundial. Con la división de Alemania, la historieta evolucionó de forma diferente en cada sector. En Alemania Occidental hubo una influencia muy marcada del espacio franco-belga y Estados Unidos, que dominaron rápido el mercado. En la Alemania del Este, la historieta se inscribió en la tradición de una educación socialista. La revista Mosaik, con casi un millón de ejemplares, fue en la RDA (República Democrática Alemana) el órgano central de una cultura de la historieta para la juventud. El origen de la historieta en Alemania está ligado al nombre de Wilhelm Busch (1832-1908), que es considerado la gran figura fundadora en Alemania. En los cincuenta la historieta sufrió la censura, fue tomada como literatura baja, "para analfabetos», «veneno anti-literario» y «anti-pedagógico». ${ }^{6}$ Esta censura, similar a lo que ocurría en los cincuenta en Estados Unidos, generó una «ley de difusión sobre escritos que son amenaza

\footnotetext{
${ }^{5}$ Knigge, A. C. «Made in Germany. Notes sur l'histoire de la bande dessinée en Allemagne», en Germanica, n. 47 (2010), pp. 1-10. Disponible en http://germanica.revues.org/1082

${ }^{6}$ Ibid., p. 4.
} 
para la juventud», que provocó una autocensura en los editores de historieta alemanes. ${ }^{7}$ Con la revolución estudiantil de 1968 y la emergencia de una nueva concepción de la vida, más anarquista, la generación «joven y rebelde» descubre la historieta underground, proveniente de Estados Unidos. A fines de los setenta y principio de los ochenta también surgieron revistas de historieta alternativas como Zomix y Hinz \& Kunz, que se convirtieron en un campo de experimentación para la nueva generación. Con la presencia de historietas anarquistas, feministas e humorísticas de creadores influenciados por la historieta underground norteamericana se desarrolló el comic alemán en los ochenta, que logró una llegada importante al público mainstream. En ese marco se puede situar el surgimiento de un nombre como Ralf König.

En cuanto a las influencias provenientes del mundo de la historieta en la obra de König, son múltiples y diversas. La crítica y el propio König han remarcado el aporte de la francesa Claire Bretécher ${ }^{8}$ principalmente porque se constata cierta coincidencia en los estilos. Elmar Klages ${ }^{9}$ señala a König como un discípulo directo de la obra de Crumb, que es considerado el nombre mayor del cómic underground norteamericano y uno de los introductores de la idea de cómic para adultos. Hay que tener en cuenta que el cómic underground surge como una más de las rebeliones sociales de fines de los años sesenta y que König ha manifestado su fascinación por Crumb, Druillet, Corben y Moebius. También se constatan influencias de autores como Charles Schultz y René Goscinny, que son considerados precursores de los cómics «intelectuales»; además, Klages nos indica la influencia de autores como Art Spiegelman y Roberta Gregory. Los nombres extranjeros en esta lista de influencias no son casualidad, ya que Alemania no tuvo una cultura de historietas tan marcada como Francia o Estados Unidos. ${ }^{10}$ Según Paul Malone, ${ }^{11}$ la introducción de la historieta extranjera en Alemania marcó a autores como König. Con la difusión de creadores como Crumb se inspiró a la primera generación importante de autores de historieta originales de Alemania.

También hay que remarcar el interés de König por relacionarse con otros autores alemanes. Ha realizado historietas en colaboración con autores como Walter Moers y ha participado

7 Algo similar a lo que ocurre en Estados Unidos como consecuencia de la publicación de Seduction of the innocent (1954, Wertham).

${ }^{8}$ Klages, E. «Elmar Klages über Ralf König», en Bartholomae, J. (comp.). Mal mir mal nen Schwulen. Das Buch zu Ralf König. Hamburgo, MännerschwarmSkript. 1996, p. 60.

9 Ibid., p. 85.

10 Alemania no tuvo una cultura de historietas demasiado popular y comparable a la de Francia o Estados Unidos. La posguerra convenció a los padres alemanes y a las autoridades de que los comics fomentaban la ignorancia y la brutalidad así como el comportamiento patológico. Esta crítica terminó en la ley contra la «Gesetz über di Verbreitung jugendefährdender Schriften» de 1953. Bartholomae, J. «Konrad und Paul verführen die Nation", en Bartholomae, J. (Hg.). Mal mir mal nen Schwulen. Das Buch zu Ralf König. Hamburgo, MännerschwarmSkript, 1996, pp. 4-10.

${ }_{11}$ Malone, P. M. «From Blockbuster to Flop? The apparent failure (or possible transcendence) of Ralf König's Queer Comics Aesthetic in Maybe... maybe not and Killer Condom", en Gordon, I., Iancovich, M., y MCallister, M. P. (eds.). Films and comic books. Jackson, University Press of Mississippi, 2007, pp. 228-230. 
en volúmenes colectivos como Wilhelm Busch und die Folgen (2007). ${ }^{12}$ Moers y König junto con Brösel (Rötger Feldmann), creador de Werner, son los tres nombres más importantes de la historieta alemana a mediados de los años ochenta. König en sus treinta años como creador de cómic no ha ignorado el campo editorial y cultural de la historieta europea. No solo por su trabajo con editoriales vinculadas directamente a la historieta, sino también por su participación sistemática en revistas de cómic de importancia para la industria de historietas europea, como las colaboraciones con Comixene, U-comix o Fluide glacial. ${ }^{13}$ Más allá de la historieta, König ha manifestado que el cine y la literatura así como otros textos culturales como la serie de animación South Park han sido influencias de importancia en su obra.

En cuanto a la recepción crítica de la obra de König, existen muy pocas intervenciones. Entre ellas destacan un artículo de James W. Jones y los enfoques de Paul M. Malone, Katharina Richmond y Hélène Boursicaut. ${ }^{14} \mathrm{El}$ artículo de James Jones, «Cartoons and AIDS: Safer Sex, HIV, and AIDS in Ralf König's Comics», describe la tematización del VIH-Sida en algunas obras de los ochenta y noventa, los trabajos de Malone y Richmond analizan puntualmente el vínculo entre historieta y versión cinematográfica, y el análisis de Boursicaut se aboca a Wie die Karnickel (2003). Más allá de estas intervenciones, no existe un trabajo global y sistemático sobre el conjunto de las historietas de König. El mayor aporte crítico a la fecha es el libro Mal mir mal nen Schwulen (1996), un compendio crítico-biográfico con entrevistas, opiniones y críticas sobre la figura de Ralf König. Aunque se trata más de un volumen de divulgación que un trabajo crítico de investigación, resulta un volumen invalorable debido a la ausencia de enfoques críticos sistemáticos. También resultan de mucho valor las ediciones críticas especiales realizadas para exposiciones de material de König, ${ }^{15}$ de las que destacan Sahnesteif. Die Krönung von RalfKönig (1996) y Der Eros der Nasen. Comics von Ralf König (2009), ambas con textos críticos, entrevistas y material inédito.

${ }^{12}$ Un volumen colectivo en homenaje al $175 .^{\circ}$ aniversario del nacimiento de Wilhelm Busch, considerado el «padre» de la historieta alemana, que contó, además de Ralf König, con la participación de Laska, Ulf S. Graupner, Volker Reiche, DuO, Flix, Martin tom Dieck, Ulf K. \& Martin Baltscheit y Anike Hage.

13 König ha colaborado en diversas ocasiones con publicaciones especializadas del medio del cómic, cito algunos ejemplos: en $U$-comix, n. ${ }^{\circ} 176 / 177$ y n. ${ }^{\circ} 180 / 181$, con motivo de las reediciones de Kondom des Grauens ante el estreno de la adaptación cinematográfica; en Comixene, n. 97 (octubre de 2006), con un número especial «25 Jahre Knollennassen-Ralf König»; en Wieselflink, n. 2 (2003), en la presentación de un autor novel con la sección «Ralf König empfiehl: Oliver Ferreira»; en Tentakel n. ${ }^{\circ} 4$ (2002) con la historieta «Der heilige Sebastian»; en Trau keinem über 30! (1998) con la historieta "Veteranen»; en Comix Eऽ Beer n. 2 (2009); en la revista Comix participa de forma continuada desde el año 2010, con historietas como «Stardust Memories» y la serie «Schutzengel $\mathrm{GmbH}$ », entre muchas otras.

${ }^{14}$ Cf. Jones, J. W. «Cartoons and Aids, Safer Sex, HIV, and AIDS in Ralf König's Comics», 2013; Malone, P. M. «From Blockbuster to Flop? The apparent failure (or possible transcendence) of Ralf König's Queer Comics Aesthetic in Maybe... maybe not and Killer Condom», 2007; Richmond, K. «Männlichkeiten in Der Bewegte Mann», 2012; Boursicaut, H. «Splendeurs et misères de quelques homos, hétéros et autres animaux: Comme des lapins de Ralf König ou la comédie de moeurs façon BD», 2010.

15 Exposiciones sobre König: Galería Janssen, Berlín, 1988; Sahnesteif. Die Krönung von Ralf König, 1996; Der Eros der Nasen - Comics von Ralf König, Ludwig Galerie Schloss Oberhausen, 2009/2010; Ich komm mir vor wie 'ne Witzfgur! - 50 Jahre Ralf König, Schwules Museum, Berlín, 2010; Ralf König. Gottes Werk und Königs Beitrag, Cartoonmuseum Basel, 2011; Elftausend Jungfrauen. Ralf König: Das Ursula-Projekt, Kölnischen Stadtmuseum, 2012/2013. 
Según datos brindados por su página web, la obra de König ha sido traducida a trece lenguas y ha vendido cerca de siete millones de ejemplares, lo que lo convierte en el autor más vendido de cómic en la historia de Alemania. Con una gran influencia en el resto de Europa, se destaca su difusión en Francia y España, países que visita habitualmente por salones y congresos de cómics. König nace el 8 de agosto de 1960 en Soest, Westfalia. Según su biografía «oficial» (publicada en su web) ${ }^{16}$ sale del armario en el año 1979. La presencia de la liberación gay-lésbica alemana resulta determinante para su coming-out. A partir de los SchwulComix comienza a tener cierta notoriedad en el submundo gay alemán. En 1987, König publica tres obras: Kondom des Grauens, Der bewegte Mann $n^{17}$ (la primera parte del ciclo de historietas que abordaré en el análisis) y Lysistrata. La primera historieta se trata de una parodia policial con recursos y esterotipos del cine negro y la ciencia ficción; la segunda será objeto de análisis en este artículo; y la tercera se trata de una adaptación en formato de novela gráfica de la comedia de Aristófanes del mismo nombre.

Der bewegte Mann y Lysistrata fueron publicadas por Rowohlt, una de las casas editoriales más importantes de Alemania, y el éxito de la primera convirtió a König en un autor referente de la historieta alemana de los años ochenta. Como señala Elmar Klages, la obra de König a partir de 1987 se configura en tres grandes líneas editoriales de acuerdo al público lector: comunidad gay, público mainstream y público lector de historietas. Aunque esta división se empieza a modificar a medida que König logra mayor independencia de las presiones editoriales hacia mediados de los años noventa con obras como Jago (1998). De los ochenta a los noventa, la obra de König se diversifica temáticamente, con trabajos vinculados a la vida cotidiana de la comunidad gay, el humor autoficcional y reescrituras de clásicos literarios, entre otros temas. En los noventa una serie de escándalos vinculados a intentos de censura por parte del gobierno bávaro dieron atención mediática a la obra de König, que junto al éxito de la adaptación cinematográfica de Der bewegte Mann (1994, dir. Sönke Wortmann), lo catapultaron como uno de los mayores íconos de la comunidad gay alemana.

\section{El ciclo Der berwegte Mann: publicación y contexto histórico}

Con la historieta Der bewegte Mann König trasciende las fronteras del mercado gay y el mercado de cómic, ya que también llega a un público que habitualmente no consumía historietas. Después de la finalización de sus estudios de arte en 1986, König había mantenido el proyecto de llegar a un grupo de lectores mayor al que estaba llegando durante el período 1981-1986. ${ }^{18}$ Como señala Malone,${ }^{19}$ gracias a la circulación de su trabajo en la comunidad gay y con la creciente aceptación de la homosexualidad en la escena underground alemana

\footnotetext{
16 http://www.ralfkoenig.de

17 Traducido al español en la edición de La Cúpula como El hombre más deseado.

18 Recordemos que por lo menos desde 1981 König busca acceder a editoriales de mayor llegada al público mainstream.

${ }_{19}$ Malone, P. M. Op. cit., p. 229.
} 
de izquierda, König había tomado la decisión de acercarse a editoriales mainstream para publicar su trabajo. Finalmente, en 1987, Rowohlt, una de las editoriales más importantes de Alemania, publica su primer cómic extenso, Der berwegte Mann, que introduce un personaje heterosexual en la escena gay alemana. Por supuesto que no fue sencillo para König acceder a la publicación en una editorial mainstream, sino que existieron presiones y censuras editoriales a las que debió acceder para poder hacerlo, ya que, entre otras cosas, Rowohlt le exigió que no hubiera sexo explícito ni penes erectos. Justamente, uno de los puntos fuertes de la práctica cultural de König en los ochenta era la visibilización del deseo y el sexo no normativo. Para la editorial, podía haber personajes gay, pero no sexo. Como señala Klages, ${ }^{20}$ König aceptó la imposición, pero de todas formas mantuvo el tono sexual habitual en sus creaciones de los ochenta. Y esto no significó el abandono de las cuestiones vinculadas a la sexualidad disidente, sino todo lo contrario, ya que logró burlar los mecanismos disciplinadores de la censura editorial y publicar lo que las editoriales intentaban disuadir. El éxito de Der bewegte Mann lo convirtió en un fenómeno editorial, lo que ha sido motivo para que Rowohlt publicara regularmente sus historietas hasta la actualidad.

Teniendo en cuenta el momento histórico de publicación de las historietas del ciclo y, en función del análisis realizado, no se puede dejar de hacer una breve mención al contexto de edición de las historietas; me refiero a la crisis del VIH-Sida. Este momento histórico-político es marco de referencia para las historietas de König de la segunda mitad de los ochenta y la primera mitad de los noventa. El VIH-Sida fue una enfermedad usada con fines políticos para atacar al modelo gay. En el giro conservador de los años ochenta, en los debates acerca de la pornografía, del rol de la mujer, de la transexualidad, entre otros, se cuela una perspectiva heterosexista que busca contrarrestar las luchas de las «minorías sexuales» en los años setenta. Y el VIH-Sida se convierte en la herramienta ideal para acabar con la «promiscuidad» homosexual, un argumento utilizado para señalar la «abyección» de la identidad gay, temas y tópicos recurrentes de las historietas de König. Las prácticas sexuales que eran representadas en los años setenta, el fist-fucking, el sexo anal, la lluvia dorada, la promiscuidad, las orgías, etc., eran prácticas moralmente inapropiadas y sexualmente indebidas para el sistema heterosexista y patriarcal. ${ }^{21}$ Estas prácticas aparecen una y otra vez representadas en las historietas de König hasta la actualidad. El VIH-Sida viene a surgir como el instrumento perfecto para normalizar y «moralizar» la identidad gay. A partir del silencio, el prejuicio, la discriminación y la exclusión, el VIH-Sida se vuelve el ejemplo perfecto para la matriz heterosexual del peligro de los excesos y el desenfreno del modelo gay. En Europa, la llegada del VIH-Sida es vista como una proyección del modelo gay norteamericano. Por ejemplo, en Safere Zeiten (1987) de König, el VIH-Sida es algo que está apareciendo en Estados Unidos y a lo que la comunidad gay alemana teme.

${ }^{20}$ Klages, E. Op. cit., pp. 56-60.

${ }^{21}$ Crimp, D. AIDS: Cultural Analysis/Cultural Activism. Cambridge, MIT Press, 1988; Llamas, R. «La reconstrucción del cuerpo homosexual en los tiempos del SIDA", en Reis: Revista española de investigaciones sociológicas, n. 68 (1994), pp. 141-172. Disponible en: http://dialnet.unirioja.es/descarga/articulo/768141. pdf; SÁEZ, J. «El contexto sociopolítico de surgimiento de la teoría queer. De la crisis del sida a Foucault», en Córdoba, D., Sáez, J. y Vidarte, P. (eds.). Op. cit., pp. 67-76 
La crisis del VIH-Sida es uno de los elementos contextuales de emergencia del movimiento y la teoría queer, así como de muchos de los textos culturales publicados en esa época como las historietas de König. Por ejemplo, en 1987, ante la inacción de la administración Reagan, ${ }^{22}$ se formó en Nueva York ACT UP, que fue uno de los primeros movimientos radicales de lucha contra el VIH-Sida, y es considerado parte de los movimientos queer; ese mismo año se publicó la primera parte del ciclo de historietas de König que analizaré a continuación.

\section{Der berwegte Mann (1987)}

Der bewegte Mann, traducido en las ediciones españolas como el «hombre nuevo» o «el hombre más deseado", es una historieta satírica ya desde su título. La palabra berwegte alude al movimiento, en un sentido físico o emocional para describir en el caso de la obra de König a un hombre que toma parte del Männerberwegung (el «movimiento de varones» de los años ochenta en Alemania) a través de un grupo de ayuda de hombres (que es representado como bastante patético). ${ }^{23} \mathrm{El}$ título indica que la obra está enmarcada en los debates del feminismo alemán de los años ochenta, así como el cambio de los roles de género en la vida pública y privada. En ese marco, se ridiculiza a los varones heteropatriarcales que se sentían amenazados ante el avance del feminismo en la sociedad: El grupo de varones heterosexuales «amenazados» ante el avance de la mujer es una gran parodia a la masculinidad hegemónica de la época, una masculinidad que está intentando imponer una figura de hombre sensible a los problemas femeninos, pero que termina siendo funcional a un sistema patriarcal (no es casualidad que el mismo año König tome como tema ficcional Lysistrata, de gran tradición en el feminismo alemán). Los varones son ridiculizados, la parodia y la burla está focalizada en el sujeto heterohegemónico. Der bewegte Mann narra la introducción de un personaje heterosexual, Axel, en el submundo de la comunidad gay, con sus fiestas y prácticas sexuales «diferentes». Los protagonistas son dos personajes gays, Norbert y Waltraud (dos amigos) y Axel y Doro (el personaje heterosexual y su novia).

Ya en este punto del desarrollo de König se puede apreciar cómo sus obras construyen un mundo propio, ya que varios de los personajes de Der berwegte Mann tienen apariciones previas en los SchwulComix. Esto es parte de la construcción de un universo ficcional propio de König, un universo Knollennasen, que se desarrolla a lo largo de toda la obra del autor. El caso paradigmático se da con Norbert, que aparecen en una historieta de SchwulComix 4. También en Zitronenröllchen (1990), que recopila historias escritas en 1986-1990, aparecen

${ }^{22}$ Como señala Llamas «la inacción institucional fue equivalente al abandono de una comunidad de cientos de miles o millones de personas a una perspectiva de muerte». Las campañas de prevención de peso no se llevaron a cabo hasta 1986 o 1987. Llamas, R. Teoría torcida. Prejuicios y discursos en torno a «la bomosexualidad». Madrid, Siglo Veintiuno de España Editores, 1998, p. 165.

${ }^{23}$ Como señala Malone respecto al título: «The book's title, Der berwegte Mann (1987), is something of a challenge to translate: here the phrase is a satirical use of bewegt, wich can mean "moved" in either the physical or emotional sense, to describe a man who is taking part in the "men's movement" (Männerberwegung) by participating in consciousness-raising support groups and so on. Thus the German title could be rendered as “The New Man” or “The Enlightened Man”». Malone, P. M. Op. cit., p. 226. 
Norbert y Waltraud en varias tiras cortas, en general de situaciones cómicas referidas a la comunidad gay alemana. En una de esas historias, previa a la publicación de Der berwegte Mann, de 1986, aparece Norbert como protagonista junto a un personaje heterosexual (que podría ser Axel) que reprime sus tendencias homosexuales. La diferencia es que la situación sexual se concreta de forma definitiva y satisfactoria para ambos personajes.

La acción se abre con Axel abandonado por Doro ante sus infidelidades y su entrada en el mundo gay de Norbert, con el que establece un vínculo ambiguo. A partir de recursos cómicos, Axel ingresa en el mundo gay y termina volviendo con Doro, pero en un juego confuso respecto a su identidad sexual. La inclusión de personajes heterosexuales que ingresan en el mundo gay se utiliza como recurso para abrir la historieta gay de König a un público heterosexual. Lo interesante es que en ese proceso parodia la heterosexualidad como categoría. König respeta las prohibiciones editoriales a nivel visual y temático, pero se las arregla para deconstruir la heterosexualidad como categoría normativa.

A pesar de la exigencia editorial de eliminar el sexo explícito, la sexualidad disidente, el deseo homosexual y la abyección se vuelven temas medulares de Der berwegte Mann. König mantiene el humor y se ríe de la heterosexualidad y el «pánico» a lo gay. La parodia alcanza también a la comunidad gay, pues la historieta se ríe de lo gay y de la irrupción de Axel en el mundo gay de Norbert. Una vez editada, la obra rompe con todas las expectativas y logra un gran éxito editorial, publicada en el sello orientado al humor Rororo Tomate. Según Paul Malone, en las historietas que publica Rowohlt König es menos franco, tiene mayores imposiciones y presiones editoriales, que salen a la luz cuando publica en sellos alternativos u orientados a la comunidad gay. Puede que Malone tenga algo de razón en esa apreciación, pero en la lectura sistemática de la sexualidad en las historietas publicadas en Rowohlt, König sigue trabajando con la disidencia sexual y la deconstrucción de la heterosexualidad normativa, de forma tal que logra burlar los controles editoriales disciplinadores de la disidencia sexual. A continuación, me interesa detenerme respectivamente en algunas cuestiones de Der berwegte Mann como la introducción del personaje heterosexual en un mundo gay, la presencia de la diva queer como la deconstrucción de la heteronormatividad, la inversión de los prejuicios de la normalidad, y la práctica de la disidencia sexual en la normalidad represiva; todas cuestiones que resultan fundamentales para la representación de la sexualidad disidente en la historieta.

La acción transcurre en la ciudad de Düsseldorf, con la Guerra Fría como telón de fondo. Se nos presenta un universo donde no se parodia lo gay sino lo heterosexual. ${ }^{24}$ En ese marco, hay una inversión de los términos: la abyección se plantea como hegemónica y la heteronormatividad es minoritaria. En el universo de la historieta existen una reconfiguración y movimiento de los roles de género establecidos por la heteronormatividad tradicional: lo masculino se feminiza y lo femenino se masculiniza, todo como un posible producto de la influencia de cierta militancia feminista en la sociedad alemana. El posicionamiento de la

${ }^{24}$ Los problemas son de los heterosexuales normativos, en el cosmos de la acción de Der berwegte Mann, por ejemplo, la «normalidad» es el nombre masculino en femenino sin que implique burla, como práctica en el lenguaje habitual en la comunidad gay alemana de los ochenta. 
mujer es muy interesante, porque cuando Doro abandona a Axel, él se convierte en el polo pasivo de una relación de género binaria.

Por otro lado, el choque entre ambos universos hace hincapié en que hay prejuicios de ambos lados: Waltraud piensa que Axel como varón heterosexual tiene algo contra los gays, a pesar de que no tiene elementos para creer eso. Pero a medida que avanza el relato, descubrimos que pese a la «apertura» de Axel, sí existen prejuicios de su parte contra las sexualidades disidentes. Lo llamativo del posicionamiento de Axel es que se da en un contexto en el que él accedería a tener relaciones intermasculinas con Norbert (pero sin abandonar su supuesta identidad heterosexual). No se puede obviar en el análisis de esta historieta el contexto de producción, ya que la obra se encuentra anclada en discusiones sobre roles de género y sexualidades propias de los años ochenta en la sociedad alemana.

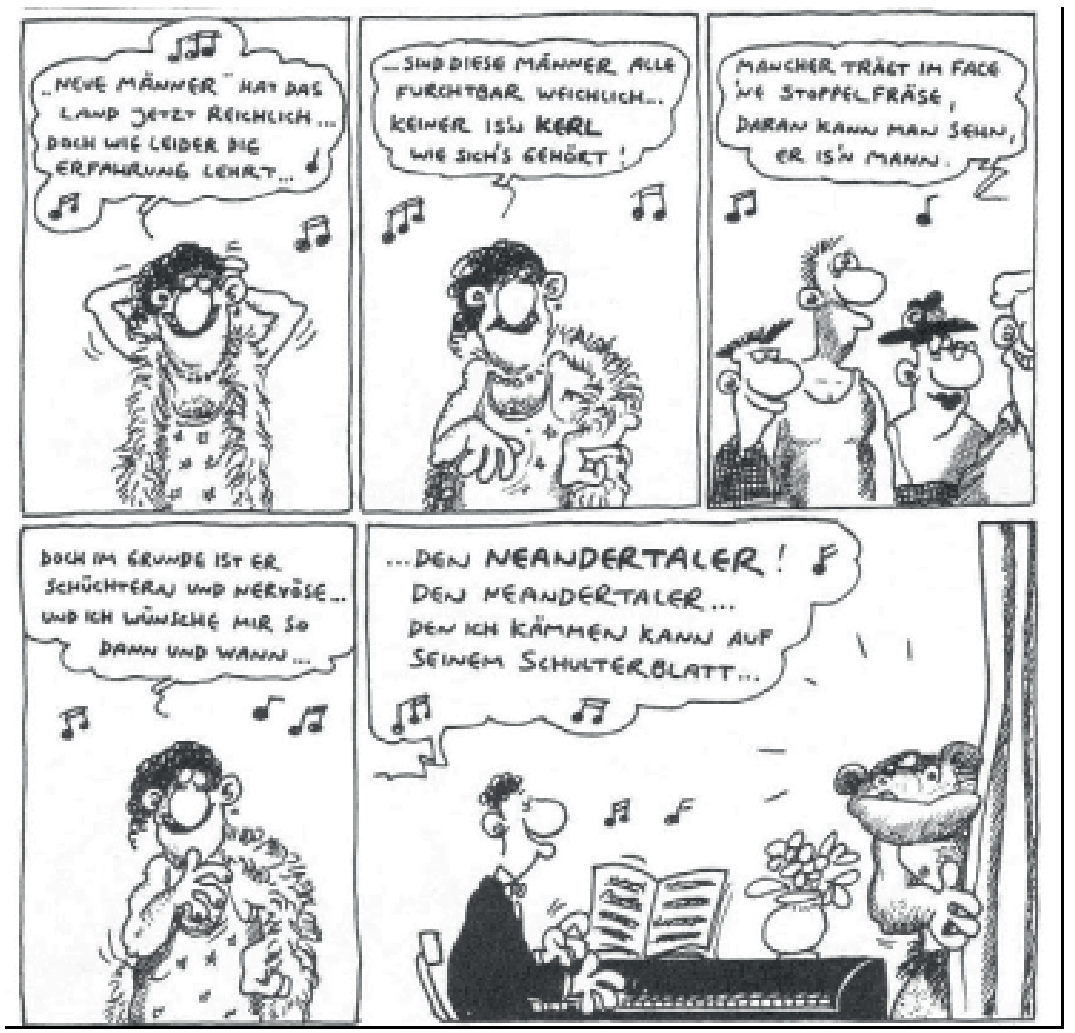

FIG. 1. KöNIG, R. Der berwegte Mann. Reinbek bei Hamburg, Rowohlt, 1987, p. 39 (detalle). Traducción propia: «"Hombres nuevos” tiene el país ahora en abundancia... pero por desgracia como enseña la experiencia... / ... Son estos hombres terriblemente blanditos... ¡Ninguno es hombre como corresponde! / Alguno lleva en la cara un papel de lija y en eso se reconoce que es un hombre. / Pero en el fondo es tímido y nervioso... y de vez en cuando deseo... /... iun neardental! Un neardental con un hombro en el que recostarme..." 
El personaje que oscila entra una y otra identidad sexual en esta obra es Axel (el «bewegte Mann» del título), que finalmente no logra una «deconstrucción» de su identidad, pero se problematiza la identidad heterosexual masculina y su vinculación con las relaciones intermasculinas del mundo gay.

La siguiente cuestión que me interesa mencionar tiene lugar en la fiesta gay en la que se produce un show drag queen. Tina Trümmer, la drag anfitriona, interpreta una canción de la diva gay alemana Hanne Wieder, ${ }^{25}$ «El neanderthal»:

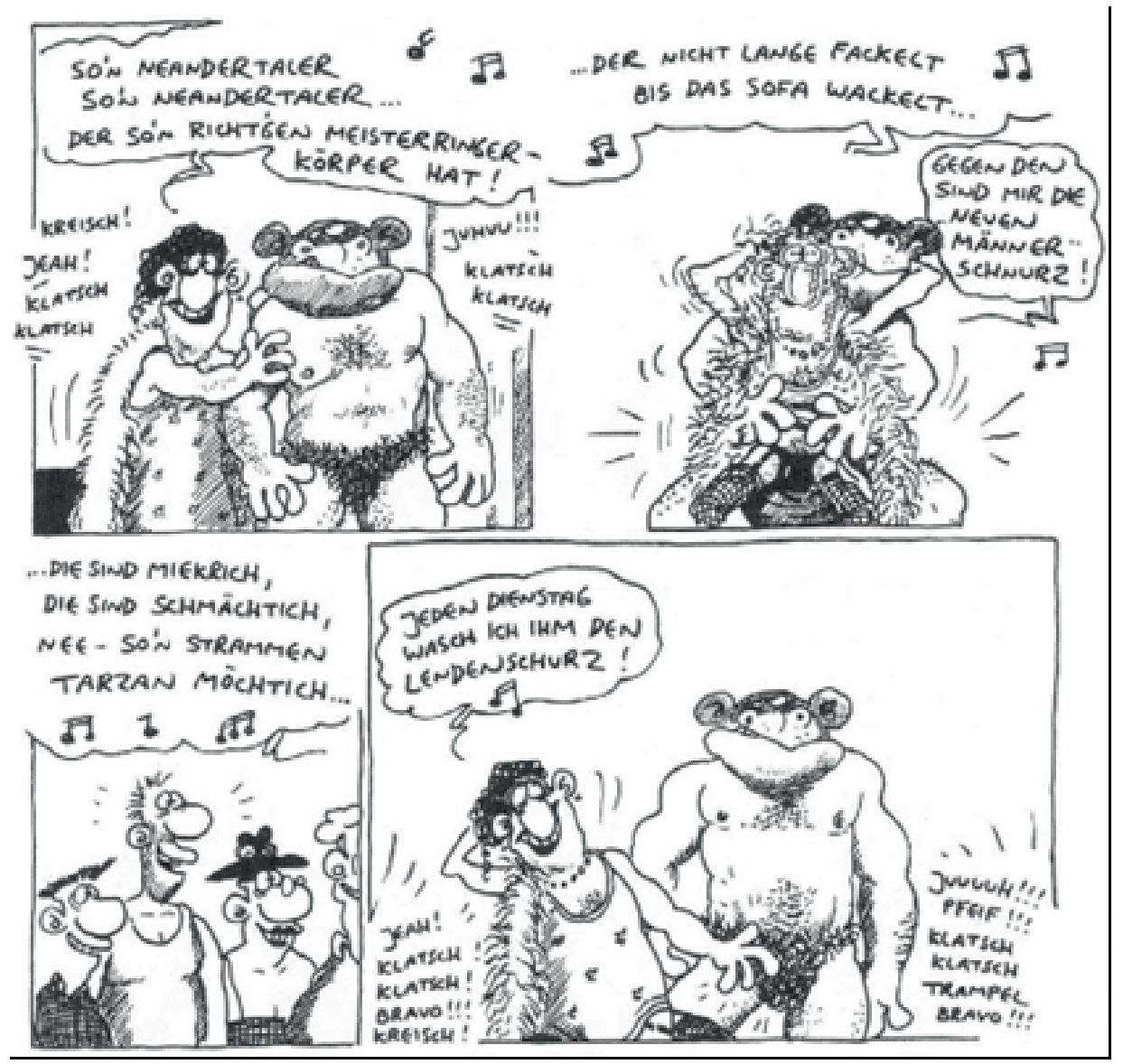

FIG. 2. KöNIG, R. Op. cit., p. 40 (detalle).Traducción propia: «Un neardental un neardental... ¡Qué tenga cuerpo de luchador! / ... Que no pierda tiempo hasta poner el sofá en movimiento... / en comparación los "hombres nuevos";me importan un huevo! / ... Son raquíticos, son delicados, nooo... Un forzudo Tarzán para mí deseo. / Cada martes le lavo el jtaparrabos!»

${ }^{25}$ Hanne Wieder es una actriz y cantante de cabaret famosa en Alemania. La canción existe y es una referencia que sigue funcionando en la adaptación cinematográfica. Wieder se trata de un icono de culto de lo gay en Alemania. 
La mención de «Tina Trümmer» tiene varias refencias: es un juego paródico con la cantante y diva gay de los años ochenta, Tina Turner; y hay también una alusión cómica al aspecto que tiene Tina, ya que «Trümmen» en alemán significa «escombros». En escena aparece un hombre disfrazado de «neanderthal»: la masculinidad heterosexual se convierte en un objeto parodiado en el show drag queen, se presenta en la historieta a lo masculino-heterosexual-normativo como el sujeto parodiado en un universo en el que lo abyecto es la norma. No se toma la canción entera por cuestiones de extensión, sino que toma una parte y modifica algunos sectores en virtud de la performance drag de Tina Trümmer, de ahí que mencione al «hombre nuevo», el varón heterohegemónico y normativo alemán en crisis:

La canción de Wieder en boca de la drag Tina se convierte en una parodia que dinamita el lugar de género heterohegemónico, y se ríe de la heteronormatividad y de cierto modelo gay normativo y binario. El público adora el espectáculo y el neandertal no puede sacarse la máscara por vergüenza. El ejemplo de Tina Trümmer podría servir para demostrar que la feminidad y la masculinidad, tanto feminizada como virilizada, son ficciones culturales a las que no importa acceder o preguntarse si existe un original.

En esta obra el tópico prejuicioso del hombre gay desesperado por el varón heterosexual se deconstruye, se juega con el mismo y se lo descentra y reconfigura, dejando al varón heterohegemónico (Axel) en el lugar de la confusión sexual, sin estereotipar al hombre gay en el lugar de seductor ante el heterosexual. Hay dos escenas muy importantes de acercamiento sexual entre Norbert y Alex; la primera ocurre cuando Axel revela (borracho) un episodio homosexual de su pasado mientras intenta seducir a Norbert; la segunda en un contexto similar pero con una referencia a la película Casablanca (1942, dir. Michael Curtiz) de trasfondo. En la primera escena mencionada, un Axel totalmente borracho se abre a Norbert, cayendo en actitudes prejuiciosas, argumentando que los gays tienen más facil el tema de las relaciones interpersonales porque no tienen que lidiar «como los normales» con las mujeres. En este punto, la borrachera parecería mostrarnos al verdadero Axel que, pese a un esfuerzo por adaptarse a la sociedad moderna en la que los roles de género son otros, no puede evitar caer en la discriminación por orientación sexual e identidad de género. Lo interesante es que el «verdadero» Axel también revela que años atrás había tenido relaciones sexuales con otro hombre, Alfons, un «artista» del tatuaje. El episodio homosexual en el pasado de Axel es descrito con claridad: cinco años atrás, en el servicio militar, ante la ausencia de mujeres (según la argumentación de Axel) y ante un varón gay que lo buscaba, accede a que le hagan sexo oral a cambio de un tatuaje. Norbert piensa que Axel justifica el episodio en una homosexualidad por necesidad (Zwangshomosexualität, justamente la palabra que se utiliza en otra obra publicada el mismo año, Lysistrata). Axel intenta seducir a Norbert mostrándole el tatuaje que tiene en la ingle, un tatuaje de una mujer realizado por Alfons, el único varón con el que Axel tuvo una relación sexual:

El tatuaje se convierte en un juego paródico/paradójico de la sexualidad del personaje heterosexual. Porque el tatuaje podría interpretarse como la marca de la relación homosexual en el pasado de Axel, una marca queer que intenta ocultar, pero que no puede abandonar y sale a la luz cuando intenta sexualizar la relación con Norbert, cuando la borrachera hace 
que la represión del vínculo homosocial (desde la perspectiva de Axel) salga a la luz. En un punto, el tatuaje le recuerda constantemente a Axel, el personaje que se identifica como heterosexual, su «caída» queer, el momento en que tuvo sexo con un varón gay.

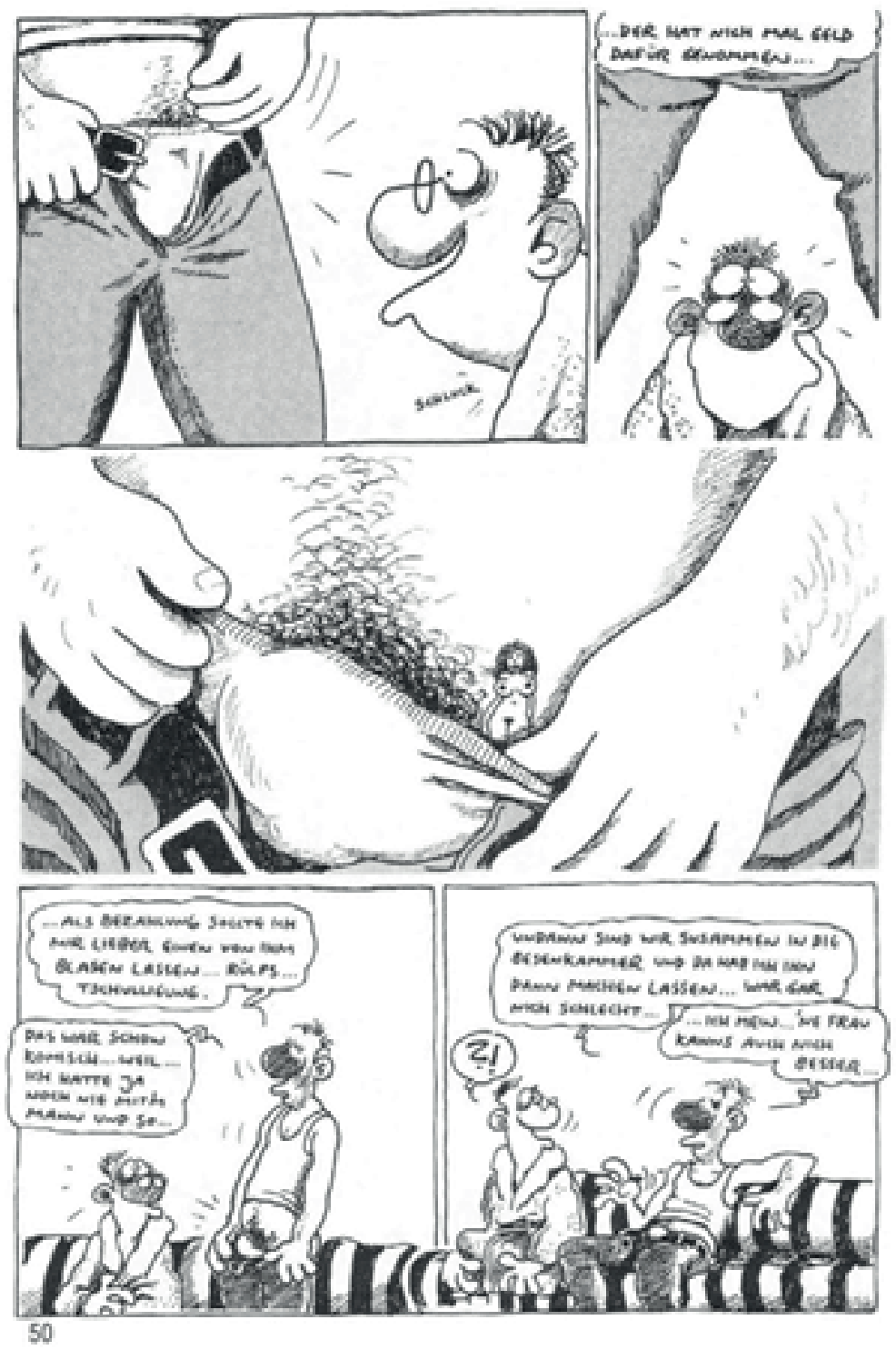

FIG. 3. KöNIG, R. Op. cit., p. 50. Traducción propia: «... Él no quiso nada de dinero por eso... / ... Como pago tenía que dejar que la chupara... Rülps... Perdón. / Eso ya era raro... porque... yo nunca había estado con un hombre y eso... / Y entonces nos fuimos juntos al cuarto de limpieza y ahí entonces lo dejé hacer... No estuvo nada mal... / ... Quiero decir... una mujer no lo hace mejor..." 
El varón heterosexual buscando el contacto sexual con el personaje gay puede interpretarse de varias formas; Axel, al ser abandonado por Doro, podría «perder» la masculinidad heterohegemónica y normativa de la que se jacta. Visualmente, en la relación sexual truncada con Norbert, Axel también ocupa un lugar pasivo, está quieto esperando que Norbert inicie una relación que él está potenciando, que en más de un sentido, él está buscando. Existen dos cuestiones importantes sobre el posicionamiento de Axel como sujeto: primero, Axel sigue viendo todo desde un lugar de valoración superior; Norbert es el externo, el diferente, el que se aparta de la norma y puede valorarlo desde otro lugar. Segundo, Axel sigue buscando a Norbert y podría jugar con la idea de que Axel-varón heterosexual feminizado perdió su nicho y privilegio heteromasculino y hegemónico y en la búsqueda de un nuevo lugar llega a pensar en la sexualidad gay como una posibilidad. Su identidad se mueve, su masculinidad heterosexual se cae cuando deja de tener a la mujer y se refugia en el mundo gay, pero ¿cómo cierra todo esto cuando descubrimos al final que decide volver con Doro cuando la reproducción biológica es una certeza? Después de sentir su heterosexualidad confrontada por la situación de sexo posible con Norbert, Axel se dirige a un cine porno heterosexual, en un intento de reforzar su heterosexualidad normativa: el pánico homosexual puede ser una interpretación de las actitudes de Axel.

La segunda escena mencionada de acercamiento sexual entre Norbert y Axel ocurre ya cerca del final de la obra. Ambos se encuentran semidesnudos mirando la película Casablanca, en toda una situación de alto contenido de seducción propiciada por Axel y en la que Norbert termina cediendo y buscando la respuesta sexual de este. Norbert y él comienzan a tener sexo oral, pero la situación es interrumpida por la voz de Doro llamando a Axel, que esconde a Norbert en el placard. Parece como si la homosexualidad latente de Axel nunca fuese a ser asumida porque no puede dejar de lado la ficción de heterosexualidad normativa. Que Norbert termine «en el placard» de Axel cuando llega su ex novia Doro es toda una definición sobre la sexualidad del personaje heterosexual. Norbert vuelve al placard: el placard de Axel tiene a Norbert dentro y Axel nunca lo acepta, lo esconde. La metáfora sobre la sexualidad no asumida de Axel es muy clara. Hay un placard y Norbert es depositado en «la oscuridad en el interior del armario» (como se llama el capítulo final en el que esto ocurre). Doro se da cuenta de que algo ocurre (y comprobamos que Axel estaba excitado porque ella menciona su visible erección) y lo cuestiona, ella sospecha que hay una mujer en esa habitación pero cuando abre el placard lo que encuentra es lo que Axel oculta: un varón gay con el que Axel tiene relaciones (que no logró consumar) y al que él mismo llevó a toda esa situación. En este punto, Axel se convierte en el varón heterosexual que esconde una identidad sexual abyecta en el placard. Pero ante la llegada de Doro, todo se desvirtúa y lo que estaba fuera del armario vuelve a entrar en él. En otras palabras: Axel tiene un hombre gay en el armario.

La heterosexualidad hegemónica termina burlándose de Norbert, porque después de oscilar con una ruptura de la matriz la misma se vuelve a rearmar y tanto Doro como Axel vuelven a sus lugares en el sistema y se sienten cómodos con ese lugar. Porque lo que no acepta el personaje heterosexual es la posibilidad de la identidad abyecta; decide priorizar sus privilegios de varón heterohegemónico ante la identidad «en movimiento» (berwegte) que propone la posibilidad queer encarnada en Norbert. Es importante remarcar que no se trata de Doro y Norbert peleando por Axel, sino más bien de dos personajes que vuelven a la matriz hete- 
rosexual y uno que queda desfasado respecto a ellos. Axel no quiere seguir viendo a Norbert y el texto menciona que resultaría raro que se siga moviendo por el ambiente gay ahora que va ser padre. Todos los prejuicios regresan, la matriz está intacta y todo se cierra con el nacimiento de un hijo y el casamiento de la pareja heterosexual.

Este «nuevo hombre» y esta «nueva mujer» alemanes siguen siendo la matriz heterosexual anterior pero con otra máscara, una que se disfraza de progresismo y aceptación, pero que carga con todos los prejuicios de la heteronormatividad. Se podría pensar que el final marca el triunfo de esta matriz heterosexual, pero el epílogo agrega otro matiz. En medio del matrimonio por la Iglesia de Doro ${ }^{26}$ y Axel, irrumpen entre los familiares Waltraud, Norbert y Fränzchen dragueados y escandalizando a la familia y novios. Ante el uso discriminatorio que hizo Axel de lo gay (Norbert) para su propio beneficio, la venganza que ejercen los personajes gays es la rebelión con humor y visibilidad; se muestran visibles y disidentes en el lugar más incómodo para la heteronorma, en el espacio de mayor rigidez sexual como puede ser la celebración matrimonial religiosa heterosexual. Doro y Axel enfurecen y ella le advierte que si los vuelve a ver se separa. Ante la discriminación, la venganza de Norbert y sus amigos se realiza con una sonrisa y en el marco más heterohegemónico de toda la obra.

\section{Pretty Baby: der berwegte Mann 2 (1988)}

Debido al éxito de la historieta, al año siguiente König publica una segunda parte, Pretty Baby: der bewegte Mann 2 (1988), que retoma a los personajes luego de la primera parte. Se continúa con los lineamientos de la obra previa, con Doro y Axel, ya casados y a punto de ser padres, y Norbert que tiene un nuevo novio carnicero y continúa con su amistad con Waltraud. Las situaciones cómicas se desatan a partir de la falta de deseo de Axel por Doro embarazada y su búsqueda de una relación sexual con una ex compañera con la que se reencuentra, Elke Schmitt. Norbert aparece como el personaje que le presta un lugar a Axel para la infidelidad con Elke, lo que termina desencadenando el final de la historieta.

Me interesa mencionar brevemente algunas cuestiones sobre tópicos que son desarrollados con mayor precisión en esta segunda parte: la ficcionalización del VIH-Sida, el juego deconstructivo de los estereotipos gay que se produce con la presencia del nuevo novio de Norbert, la visibilización de situaciones de violencia sobre la disidencia sexual y la referencia explícita al film Muerte en Venecia (1971, dir. Luchino Visconti) como obra de la tradición gay.

En primer lugar, me interesa marcar que, una vez más, el principio ordenador del cosmos de la historieta es el mundo gay, un mundo no-heteronormativo. La crisis de pareja que da título al capítulo no es la de Doro y Axel, sino la de Norbert con su novio, el carnicero (un personaje original de la segunda parte). Desde el principio se señala que no son una pareja

${ }^{26}$ Doro es retratada como un sujeto que trasciende los roles de género mientras no está con Axel, cuando vuelve a la matriz heterosexual y decide tener un hijo se la equipara con Axel como parte de un sistema heterosexual. 
que vaya a funcionar, ya que Norbert es vegetariano. ${ }^{27}$ En el novio de Norbert se juega con los prejuicios del mismo estereotipo gay y se realiza una inversión de la situación del personaje gay en el placard, en este caso un personaje gay que no sabe que es heterosexual, en una parodia que sigue jugando con las identidades en movimiento que podemos inferir a partir del título. El berwegt en esta obra no sería Axel, sino que podría ser el novio de Norbert, que termina en pareja con una mujer y esperando un hijo.

En esta segunda parte los prejuicios de la heteronormatividad sobre el modelo gay quedan mucho más exhibidos en discusiones en la que se habla de la homosexualidad. Doro le reclama a Axel su «posible» homosexualidad, producto de haberlo encontrado en la cama con Norbert en la primera parte. Cuando discuten sobre estas cuestiones se vuelve a mencionar el VIH-Sida y entran en juego el pánico moral, el desconocimiento sobre el tema y el prejuicio discriminador. Mientras ellos discuten y luego intentan tener relaciones sexuales (fallidas), una pareja de vecinos mayores escucha sus discusiones y en ellos se juegan (igual que con Axel y Doro, pero con diferencias de matiz generacional) los prejuicios sobre lo gay y, en particular, de todo el tema del VIH-Sida, su surgimiento, desconocimiento y los prejuicios en torno a la epidemia en Alemania. En el diálogo hay varias referencias culturales puntuales, más que nada referidas al VIH-Sida y al mundo televisivo norteamericano: Richard Chamberlain, Rock Hudson y Denver-clan. ${ }^{28}$ Lo interesante es que la pareja (totalmente heteronormativa) confunde todo y lo carga de prejuicios, primero con homofobia, marcando que Chamberlain y Rock Hudson tienen VIH-Sida. Y a partir de esa afirmación también Linda Evans tendría sida, más allá de lo «sana que parece», porque usa peluca y ya está como los «enfermos» de sida, «sin pelo y sin dientes». Y Blake Carrington (John Forsythe) también tendría sida. En momentos confusos a nivel popular sobre las formas de exposición al virus (y cargados de prejuicios y homofobia), la pareja de vecinos actúa de la peor forma; incluso podemos pensar que la acusación hacia Linda Evans tiene también un componente fuerte de discriminación de género (una mujer es la que está transmitiendo el VIH-Sida entre los actores de Denver-clan).

También en el diálogo de los vecinos se mencionan situaciones de políticos alemanes y su actuación frente a la epidemia de VIH-Sida. Se hace referencia a dos posiciones políticas, una más progresista, Rita Süssmuth, y otra de derecha, en Baviera, Gauweiler. Que König esté planteando todo este asunto en este contexto no es una casualidad, ya que se trata del

${ }^{27}$ Se abre la obra con las diferencias entre ellos por el cine de terror, con el carnicero que mira películas como Der Frikadellenmörder von Manhattan (El triturador de Manhattan) y luego Die Rückkehr der Killerkondom (El retorno del condón asesino). La referencia al cine de horror está cruzada por la apreciación de Waltraud de que el «extraño amigo» de Norbert no tiene sensibilidad (según Waltraud, la sensibilidad propia de los gays) y con la referencia a la misma obra de König en la alusión a Kondom des Grauens.

${ }^{28}$ Richard Chamberlain fue víctima de la campaña en contra de supuestas estrellas homosexuales en el momento de emergencia del VIH-Sida. Como señala Richard Dyer, también hay vínculos entre el VIH-Sida en Rock Hudson y su actuación en Dinasty junto a Linda Evans. Recordemos que Rock Hudson muere en 1985 de sida y se convierte en la cara visible de la enfermedad. Antes de su muerte, había actuado en Dinasty y hubo una famosa escena de un beso con Linda Evans que generó un gran escándalo. Dyer, R. «Rock: The Last Guy you'd have figured?», en Dyer, R. The Culture of Queers. Londres/Nueva York, Routledge, 2002, p. 162. 
año 1988: la incomprensión, el prejuicio y la discriminación son la regla sobre el VIH-Sida a nivel global. Él posiciona la problemática respecto a Estados Unidos y la política interna alemana. Lo interesante es que está poniendo en un contexto humorístico los prejuicios que imperaban en la sociedad y los está deconstruyendo. Hay una gran parodia pero al mismo tiempo una deconstrucción del tema y del prejuicio. Porque Axel y Doro, aunque no son el personaje ridiculizado conservador y de derecha (como lo son los vecinos), también piensan o pensaron cuestiones similares respecto al VIH-Sida y la comunidad gay. Es muy valorable cómo está presentado el tema en una historieta pensada para un público mainstream y no específicamente publicada dentro del circuito gay.

El capítulo final contiene una referencia explícita a Muerte en Venecia. Cuando Norbert le presta su casa a Axel para que pueda acostarse con Elke, van al cine con su novio y Waltraud. La película de Visconti es todo un icono del modelo gay y de la construcción de un pasado homosexual; en la historieta se hace presente en montajes del afiche y en reconstrucciones visuales de escenas (FIG. 4 y FIG. 5).
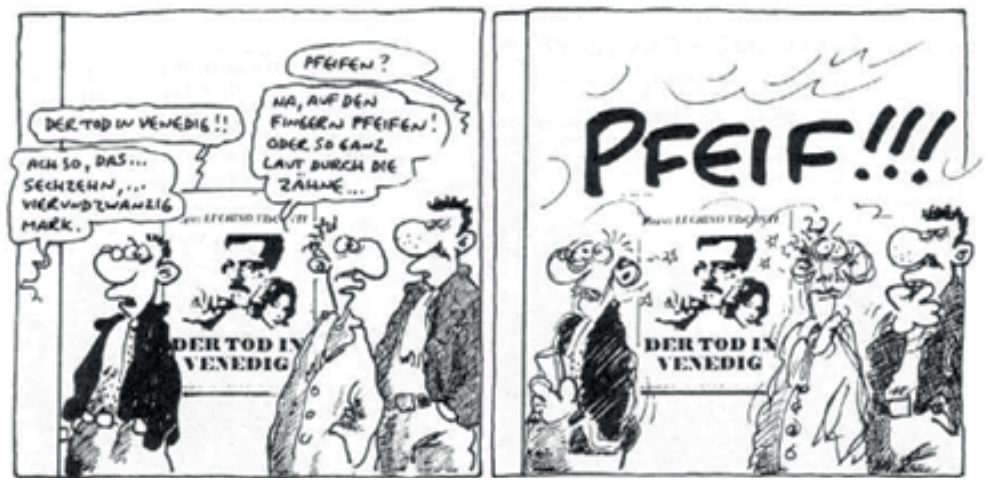

FIG. 4. König, R. Pretty Baby. Der berwegte Mann 2. Reinbeck bei Hamburg, Rowohlt, 1988, p. 84 (detalle). Traducción propia: «iiMuerte en Venecia!! / Ah, bien, 16... 24 marcos. / ¿Silbar? / Sí. ¡Silbar con los dedos! O muy fuerte entre los dientes..."

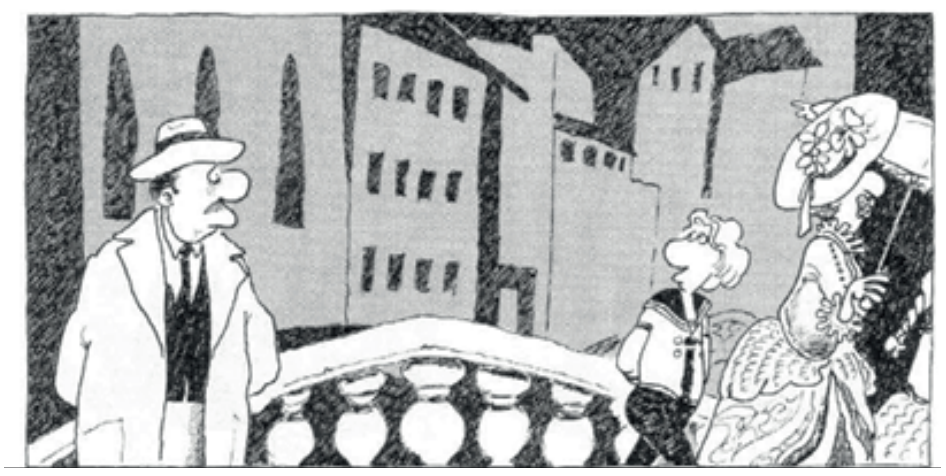

FIG. 5. KöNIG, R. (1988), Op. cit., p. 92 (detalle). 
En el cine, un grupo de personajes heterosexuales ingresan por error a ver Muerte en Venecia y se termina produciendo un episodio de violencia homofóbica contra Norbert, su novio y Waltraud, mientras en la pantalla se reproducen escenas del film (FIG. 6).

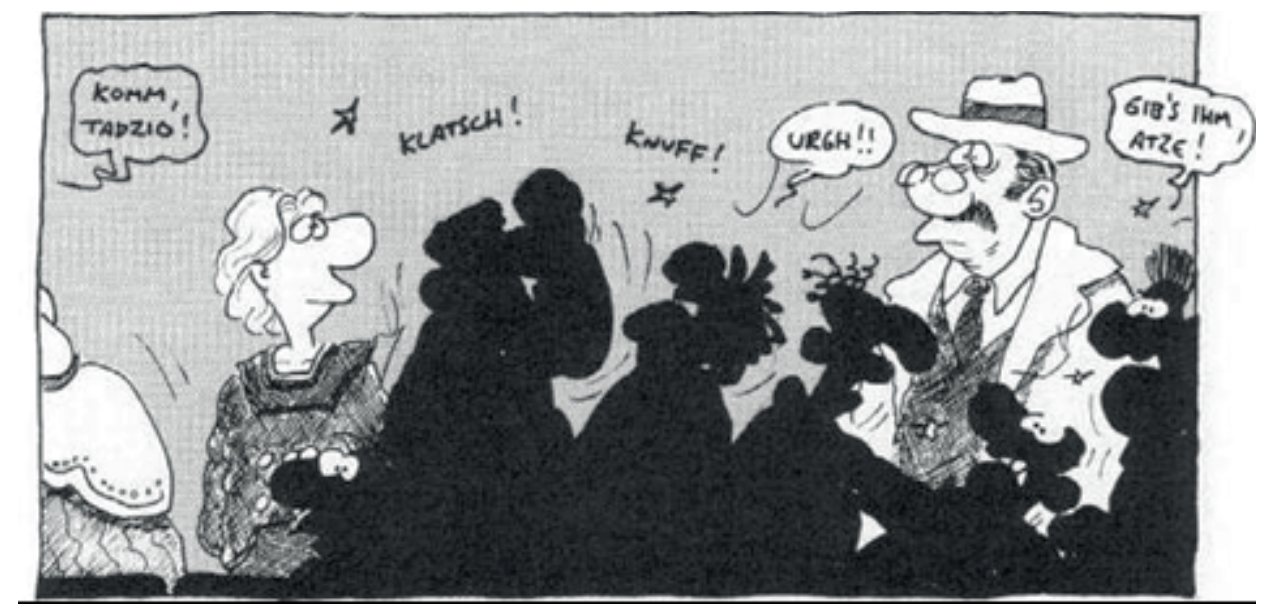

FIG. 6. König, R. (1988), Op. cit., p. 94. Traducción propia: «iVen, Tadzio! / [onomatopeyas de golpes] / ¡U Urgh!! / ¡Dale, Atze!»

Esta cuestión nos sirve para pensar en la visibilización de la violencia y la homofobia, que resulta recurrente (sin perder el dispositivo cómico) en el conjunto de la obra de König.

La obra concluye con Doro dando a luz y perdonando la infidelidad de Axel con Elke Schmitt. En el cierre hay una idea final que indica que Waltraud y Norbert se quedan con la diversión y Doro y Axel con la matriz heterosexual. Porque después de toda la radiografía interna que se hizo de la relación heterosexual y todo lo que ocurrió en Pretty Baby, ese matrimonio tiene muy poco de amor y armonía, más bien está construido sobre una matriz que resulta totalmente ficticia, una matriz artificial, una ficción de normalidad que hace agua y que la realidad heteronormativa los lleva a mantener. El epílogo es una página ilustrada adornada con una especie de poema satírico en el que se contraponen las dos parejas que terminan formando parte de la matriz heterosexual y se convierten en familias procreadoras. Se marca un destino manifiesto para la heteronormatividad: «multiplicarse». La idea es que la matriz es una gran ficción que fracasa y se constituye como una adecuación identitaria disciplinadora de los sujetos y los cuerpos.

\section{Consideraciones finales}

El ciclo Der berwegte Mann, con sus dos partes pensadas como una totalidad, permiten evidenciar los intereses de la obra de König hasta nuestros días, así como el interés de König de posicionarse como autor gay de historietas en el campo cultural alemán. La aparente «adaptación» de los contenidos de König a una editorial como Rowohlt se trata simplemente de una estrategia para combatir los mecanismos de disciplinamiento del mercado 
editorial en los años ochenta, ya que, pese a aceptar la prohibición sobre la representación de la práctica sexual explícita, König continúa en ambas obras manteniendo la construcción ficcional de universos vinculados a la sexualidad disidente y en los que la hegemonía del cosmos ficcional pertenece a la disidencia de sexo/género. En ese sentido, en ambas obras se puede evidenciar una crítica muy marcada, a tono con los debates del feminismo alemán de los años ochenta, de la heterosexualidad normativa y los mecanismos de dominación del heteropatriarcado. Todas estas cuestiones, que abren la trayectoria de König en un mercado editorial mainstream, se convierten en líneas que se desarrollan en los trabajos publicados por el autor en las décadas posteriores, hasta constituirse en temas medulares del conjunto de la obra de König.

En 2012 se estrena el film documental König des Comics de Rosa von Praunheim. Se trata de una exploración de la figura de Ralf König como autor. El documental se estrenó en el festival internacional de Berlín en febrero de 2012. No es casualidad que un cineasta como Rosa von Praunheim tome la figura de König y sus historietas como tema a retratar en una película documental. Porque la obra de König es un continuum que defiende, problematiza y confronta los estereotipos y la representación social de las sexualidades disidentes en Alemania desde principio de la década de los ochenta a la actualidad. La obra de un autor como Ralf König puede funcionar como testimonio cultural de la situación de las sexualidades disidentes en Alemania en las últimas tres décadas, con una influencia muy fuerte del modelo gay norteamericano. Se puede trazar una línea que comienza en el modelo gay de los setenta, el que hace que König se asuma y se sienta parte de un colectivo, justamente el modelo que él busca representar y para el que él escribe, continúa con la crisis del mismo ante la catástrofe del VIH-Sida y la decadencia del modelo de los noventa y la pervivencia de la subversión. En definitiva, Ralf König ha creado en las últimas tres décadas una obra compleja y diversa que se centra en una representación visible de la sexualidad disidente que va de la mano de los procesos de la disidencia sexual vividos desde los años ochenta al siglo XXI. 


\section{Bibliografía}

Bartholomae, J. «Konrad und Paul verführen die Nation», en Bartholomae, J. (Hg.). Mal mir mal nen Schwulen. Das Buch zu Ralf König. Hamburg, MännerschwarmSkript, 1996, pp. 4-10.

Ceballos Muñoz, A. «Teoría rarita», en Córdoba, D., Sáez, J. y Vidarte, P. (eds.). Teoria Queer. Politicas Bolleras, Maricas, Trans, Mestizas. Barcelona, Egales, 2005, pp. 165-178.

Crimp, D. AIDS: Cultural Analysis/Cultural Activism. Cambridge, MIT Press, 1988.

Doty, A. Flaming Classics. Queering the Film Canon. New York, Routledge, 2000.

Dyer, R. «Rock: The Last Guy you'd have figured?», en Dyer, R. The Culture of Queers. London/New York, Routledge, 2002, pp. 159-174.

Klages, E. «Elmar Klages über Ralf König», en Bartholomae, J. (comp.). Mal mir mal nen Schwulen. Das Buch zu Ralf König. Hamburg, MännerschwarmSkript, 1996, pp. 56-87.

Knigge, A. C. «Made in Germany. Notes sur l'histoire de la bande dessinée en Allemagne», en Germanica, n. 47 (2010), pp. 1-10. Disponible en http://germanica.revues.org/1082

König, R. Der berwegte Mann. Reinbek bei Hamburg, Rowohlt, 1987.

— Pretty Baby. Der bewegte Mann 2. Reinbeck bei Hamburg, Rowohlt, 1988.

Llamas, R. «La reconstrucción del cuerpo homosexual en los tiempos del SIDA», en Reis: Revista española de investigaciones sociológicas, n. ${ }^{\circ} 68$ (1994), pp. 141-172. Disponible en: http://dialnet.unirioja.es/descarga/articulo/768141.pdf

- Teoría torcida. Prejuicios y discursos en torno a «la homosexualidad». Madrid, Siglo Veintiuno de España Editores, 1998.

Malone, P. M. «From Blockbuster to Flop? The apparent failure (or possible transcendence) of Ralf König's Queer Comics Aesthetic in Maybe... maybe not and Killer Condom», en Gordon, I., IAncovich, M. y MCallister, M. P. (eds.). Films and comic books. Jackson, University Press of Mississippi, 2007, pp. 228-245.

Praunheim, R. von. König des Comics. Deutchsland, Rosa von Praunheim Filmproduktion/ZDF, 2012.

Preciado, P. B. Testo yonqui. Madrid, Espasa, 2008.

SÁEz, J. «El contexto sociopolítico de surgimiento de la teoría queer. De la crisis del sida a Foucault", en Córdoba, D., Sáez, J. y Vidarte, P. (eds.). Teoría Queer. Políticas Bolleras, Maricas, Trans, Mestizas. Barcelona, Egales, 2005, pp. 67-76. 